\title{
AN INTRODUCTORY COURSE IN READING FRENCH
}

\author{
Robbins Burling 1 \\ University of Michigan
}

\begin{abstract}
Students who wish to read French and who are willing to omit instruction in the spoken language have learned successfully by using texts that are mixtures of French and English. The texts begin with English words in French word order, and in subsequent passages a few French words are substituted for the English words. Later the proportion of French gradually rises. The method has the advantage that adult students can practice from the beginning with adult materials. They need never be subjected to the French equivalent of "Dick and Jane". The method also allows a relatively systematic introduction of grammatical material, another advantage for the adult student, and it allows a good many aspects of the language to be absorbed relatively unconciously through extensive exposure to written matierals. Its major disadvantage is the unaesthetic appearance of the mixed texts. The method violates a number of widely held assumptions about second language instruction but reasons exist for doubting all these assumptions.
\end{abstract}

In the following pages I will describe an unconventional method that I have been using to help people learn to read French. I begin by offering students a reading passage that is an almost literal word for word translation from French into English. It has English words in French word order. A text of this sort quickly conveys a sense of the overall patterns of French sentences. In subsequent passages the most common French words are introduced into the reading materials where they take the place of their English equivalents. Step by step an ever larger proportion of French words appears in the reading passages and the text turns

1I first proposed the method that I describe in this paper ten years ago in an article in Language Leanring (Burling 1968). The method was suggested, in part, by the experience of friends who had told me about learning to read the interlineal translations found in some linguistic texts. I have also known about the Yale Chinese series in which characters are introduced gradually and progressively, in a text that is otherwise romanized. $R$. Tongue has experimented with a method much like mine for teaching Indonesian to English speakers: Reading Bahasa Indonesia (mimeographed, no date).

I am indebted to the Center for Research on Learning and Teaching at the University of Michigan which provided a small grant that allowed me to hire a research assistant. The assistant, Norma Ware, did a valiant job in organizing and cleaning up my manuscript in preparation for its first full scale trial. I am also much in debt to Professor Raymonde Carroll of the Romance Languages Department for her assistance and her encouragement. 
progressively into French. Starting with a text that a monolingual English speaker can understand with no more than a minimum of explanation, the student is led, by gradual steps, to a text that is written in French.

My method is strange enough thay many teachers of foreign languages may feel that it passes beyond the bounds of unconventionality and reaches the bizzare. It requires a text that is written in a mixed language and, at first sight, this may appear to be more ludicrous than useful. Students spend their time practicing with a text that is neither fish nor fowl but that fluctuates uncertainly between the two.

The final judgement about any method of language instruction must, however, be the pragmatic one: can students use the method to learn the language? Once I have explained the rationale for my suggestions, given concrete examples of the stages through which I have been guiding students, and pointed to the considerable advantages of the method, I hope that many readers will agree that I am offering a technique that deserves a serious trial, and I even hope that a few will be stimulated to try similar experiments.

\section{Popular But Dubious Assumptions About Language Pedagogy}

Language pedagogy seems to have drawn to itself more than its share of hoary assumptions. Some of these assumptions claim such nearly universal acceptance that no one bothers to make them explicit. They may be barely even recognized. I want to point out a few of the assumptions about language teaching that seem pervasive in the 1970's for I believe there is good reason to doubt them. Once the assumptions are questioned, my pedagogical proposals may seem more plausable than they appear on first sight.

I will consider four assumptions that appear to be widely, if not quite universally, held by teachers of foreign languages. I feel there are good reasons for doubting all four.

1. The Primacy of Oral Over Written Language. It is obvious that children learn to speak before they learn to read and write. Linguists take spoken language to be the subject of most of their investigations and they see writing as derivative, as a form that is secondary to the spoken language. My fellow linguists seem to have convinced most teachers of elementary languages that it must follow from these facts that spoken language should also have priority in second language instruction. Such a conclusion, however, should not pass unquestioned. In real life people do learn to read, for pleasure and for profit, in languages in which their 
control of the spoken language is minimal. For many students learning to read is a practical goal, a goal for which they can envision a realistic use. Learning to speak is a more remote possibility, one that is less likely to seem within useful reach. Students who want to learn to read but who would like to avoid the difficulties posed by the spoken language deserve to be taken seriously.

2. The Integral Unity Of A Language. Most linguists (and, I suspect, most language teachers) seem to assume that the various aspects of a language are all rather tightly interdependent. Pronunciation is related to grammar and grammar to vocabulary. The noun phrase cannot be fully understood without understanding the verb phrase. Case suffixes relate to everything, and so it goes. In some abstract sense statements of this sort are surely correct, but in the practical world where students live the parts of a language are not always so tightly joined. When we hear someone speak grammatically fluent English with a strong foreign accent we should realize that we have found a person who has learned some aspects of our language (grammar, vocabulary) but who has failed to learn another (pronunciation). Total control of a language requires a knowledge of all its aspects, but beginning students cannot possibly have total control. Our feelings about the unity of a language lead us to hope that our students can develop skills in all areas from the very beginning. We drill them on pronunciation, we teach them vocabulary and we give them bits and pieces of grammar so that they can produce and understand whole sentences. They might make more satisfying progress if we could devise a means by which they could take up these topics one by one.

3. Inviolable Boundaries Separate Different Languages From One Another. This is really the obverse of the last assumption, for just as we take each language to have an internal unity, we also imagine the boundaries between different languages to be sharp and unbridgeable. Here again, however, practical experience shows our implicit assumption to be false. The person who speaks with a strong foreign accent not only demonstrates the lack of unity of a single language, but he also demonstrates the ease with which languages can be mixed. He communicates with the grammar and vocabulary of one language but with the phonology of another. Speakers of languages such as Hindi and Burmese who have a substantial knowledge of English feel free to use any English word that they think will be understood. The ease with which vocabulary flows across the language boundary is strikingly evident when 
scientific or technical matters are discussed in these languages but the same processes can be observed in many other areas. Many Indians and Burmese speak a language that is Hindi or Burmese in grammar and phonology, but that draws, almost at will, upon the English lexicon. We can hear the same sort of language among immigrants to the United States. they may use the syntax and phonology of their native language but they also draw freely upon English vocabulary when refering to things American.

Every school child who ever studied a foreign language must have made up sentences of mixed antecedants: Scramez-vous; What mangez-vous for dinner ce soir? He has away ge-gone. We do not usually take such linguistic antics seriously. We regard them, rather, as the frivolous games of school children. But the games do demonstrate the ease with which all of us can mix our languages, and they demonstrate the permeable nature of the boundaries between languages. Perhaps we should take our skill at mixing languages more seriously, for we might be able to build upon this skill when we try to help our students learn a new language.

4. Language Production Goes Hand In Hand With Comprehension. It is obvious that, at any given stage of his development, a small child's receptive ability in his first language outstrips his productive ability. In foreign language programs, however, we almost always expect a student to be able to say just about anything that he can understand.

Of all the assumptions about foreign language learning, it is this that I find most dubious. One reason for insisting upon production, I fear, is that it is easier than reception to test. When we ask our students to speak or to write, their mistakes show up immediately. It is easy to decide who merits an A and who must be content with a $\mathrm{C}$. Testing comprehension is not quite so easy. Questions must be phrased a bit more carefully. The answers to be sought are a shade more subtle.

Ease of testing hardly offers legitimate grounds for deciding what to teach but there are other, superficially more plausible, reasons for feeling that production should go along with reception. Perhaps it is felt that a "mere" receptive ability will not get anyone very far when he needs directions in Paris. Even more important, it may be supposed that language is a kind of "behavior" and that learning a new behavior requires practice and drill.

I find neither of these arguments persuasive. Most students will never get to Paris, but all will have the opportunity to read, and $I$ argue at some length below that a focus upon receptive skills 
would cut through many of the most serious problems associated with introductory language instruction. The concept of language as a form of "behavior" for which mechanical practice is necessary seems to me to constitute the most serious of misunderstandings. There is ample evidence that it is possible to learn to understand oral language without being able to speak it, and many people have learned to read without gaining any confidence in their ability to write. Production is inhibiting because mistakes show up so quickly. Concentration upon reception allows the student to focus upon meaning-the area of language that is important to everyone except the linguist-and to let the mechanics of the language recede to the background. A strong and, to me, entirely convincing argument for postponing deliberate instruction in production has been made in a number of places by Valerian A. Postovsky (1974, 1975).

If we remember the way in which children learn their first language we may come to feel that emphasizing receptive skills would be a promising way to teach a foreign language.

\section{The Example of First Language Learning}

Those who propose techniques of language pedagogy are continually tempted to justify their suggestions by reference to the way in which a child learns his first language. Proponents of different methods refer to different facets of the child's learning process, however, and few would argue that adults should follow the child's patterns in every respect. We should hope that an adult's broader experience will give him some advantages over a child. We ought to ask which aspects of second language learning can best follow the example of first language learning, and which other aspects can be made easier for adults by deviating from the methods of small children. I suggest that we should draw two lessons from the example of children.

First, I believe we would make more rapid progress if the initial stages of language instruction would emphasize comprehension and minimize attention to production. By concentrating upon comprehension we would avoid several problems. A student would not face the embarrassment of his inevitable mistakes. He would not be subjected to the terrible examples of his classmates' feeble efforts. He would not have to focus upon retrieving difficult new words from memory but could concentrate upon the far less difficult task of recognizing words. The learner, moreover, could almost entirely avoid conscious attention to some annoying details. 
When learning a second language such as French or German by conventional methods, for instance, gender is a constant headache and a constant source of error. If comprehension were emphasized gender would pose few problems. The student would, to be sure need know that gender exists. When studying French he would need to know that $l e$ is used with some words and $l a$ with others, but he would not need to struggle to memorize which form of the article goes with which word. The passive learner could allow many other fussy and irregular apsects of the language to slip by just as lightly.

This brings me to the second way in which second language learning ought to profit from the example of children. Children learn the fussy details through long exposure. By the time they are getting these details right most of the time, they have had years of passive experience. This allows them to sense that some phrasings do not "sound right". They can monitor their own speech and they need expend little conscious effort in mastering all these details. Second language learners ought to be able to learn the fussy details with no more struggle than children.

In some other ways, however, adult learners have advantages over children and we ought to capitalize upon these advantages. The primary adult advantage would seem to lie in the ability to see the large picture. Broad patterns can be explained to adults and they can quickly grasp generalizations that might take long hours to induce from examples. The English speaking student of French can be told that adjectives follow nouns and that pronoun objects preceed verbs and in this way he will avoid a good deal of puzzlement that might arise if he had to discover these generalizations, as a child must, by inducing them from examples. The nature of the gender system can be explained but the details of which nouns are masculine and which are feminine can be left for slow, child-like, absorption. The nature of the tense system can be explained but the multiplicity of irregular details in a language such as French can be left to a much more extended learning process.

\section{Sequencing}

I believe we should think harder than we have in the recent past about how to help those students whose primary goal is reading. I suggest that we could lighten the task of language learning if we would not require a student to produce the foreign language but let him concentrate, instead, on the easier tasks of 
recognition and comprehension. We could release the student who wants to read from the struggles with pronunciation that anyone who tries to talk must face.

I also feel that we could capitalize upon our ability to mix languages. We could start with the student's familiar native language and systematically introduce aspects of the new language into this familiar context. This would allow the student, at every stage, to practice with fully adult material. Whatever materials students find interesting can be adapted to this method. No one should ever be reduced to the level of Dick and Jane. If materials of high intrinsic interest were used students would be motivated to continue not only from a long-term desire to learn the language, but also from a short-term eagerness to find out what is happening in the book or story that they are reading. Concentrating upon only one aspect of the language at a time would allow rapid progress, so that students could have a real sense of accomplishment.

My proposals also allow a radical reordering of the sequence of topics that is presented to the student. It becomes possible, in particular, to present grammatical materials more systematically and more usefully than in conventional language courses. In the next section I give a detailed outline of the sequence that I have developed for teaching French, but the major point is that the method allows the most general and pervasive features of the language to be presented first while the fussy irregularities can be postponed until later. In a conventional course, when the students are expected to speak from the start, the very first lesson must touch upon everything. It must include something about pronunciation; it must introduce words of several grammatical categories; it must at least hint at a few rules of grammar so that the words can be joined together into meaningful phrases and sentences. When so many topics must be touched upon no one of them can be dealt with in any depth. Each topic of grammar (pronouns, tenses, the gender system, etc.) comes typically to be spread across many lessons, and the student has trouble gaining any overall perspective of the linguistic processes involved. He is told about a thousand little details, details that he needs if he is to avoid mistakes in production; but at the same time he is likely to miss any general feeling for how the language is put together. His conscious attention is focused upon precisely the wrong part of the language. Details that should be left for slow, even unconscious, absorption become a constant conscious headache. The general, more pervasive, aspects of language can only be dimly perceived. 
With the method I propose here it becomes possible to present a general description of a linguistic process, introduce the major features of that process into the text as a block, and then leave the irregularities and details to be gradually absorbed through long exposure. In French, for instance, gender and number work together in an interrelated system that is expressed through articles, adjectives and nouns. This system can be explained in a few paragraphs and the French forms of the articles and of the adjective suffixes can then be introduced into a practice text. The context into which these new forms are introduced can be entirely familiar and this allows the learner to focus his attention upon what is new. The overall principles of the system can be learned quite easily in this way, while its irregularities (such as the irregular feminine and plural forms of many French adjectives) will be learned more slowly. When active production is required these processes take much longer to learn, but if the principles of the system are clear and if active production is not needed, the irregularities can gradually fall into place without much difficulty. Many other aspects of the language can be introduced in the same way as the gender-number system.

\section{The Lessons}

In order to give a concrete idea of the program that I have developed this section gives a lesson by lesson outline of the sequence through which I have been leading students. Short passages adapted from "La derniere classe" by Alphonse Daudet illustrate some of the levels through which students move. I will explain a number of special conventions as they arise.

1. Word Order. The first and most pervasive aspect of French to which students must grow accustomed is word order. Where French word order is like English nothing needs to be said, but I do explain that 1) object pronouns preceed verbs, 2) adjectives often follow nouns, 3) negatives come in two parts that surround the verb, 4) subjects and verbs are more regularly exchanged to form questions than in English, and 5) the definite article is sometimes used in French where it would not appear in English. The only French words that I use at this stage are the most common words for negation-ne...pas. English equivalents for these could be found, but they would be so artificial that the simpler solution seems to be to introduce this single French form from the very beginning. Many details of French word order can be passed over in silence. Even where the order differs slightly 
from English, the meaning will often emerge quite easily and students will soon become accustomed to the French pattern through the examples in their reading. I use French punctuation from the start. With this as a background, students have no trouble with passages such as this:

That morning-there I was very late for to go to the school, and I had great fear of to be scolded, all the more that Mr. Hamel us had told that he us would question on the participles, and I ne of them knew pas the first word. A moment the idea to me came to miss the class and to take my course across fields.

2. Gender and Number. As noted earlier, gender and number unite French articles, adjectives and nouns into a single system. I describe the system in a few pages. The masculine, feminine and plural articles are given (un, une, le, la, les) as are the regular adjective suffixes for gender and number $(-e,-s$, $-e s)$. Since the prepositions $\dot{a}$ and $d e$ form common contractions with the articles, it is convenient to describe them at the same time and to introduce both their free forms and their contractions with the articles $(d u, a u x$, etc.). All these French forms are then introduced into a reading passage. Students read a passage at the level of the sample given next and they quickly gain a feeling for the way in which these words are used in context. The French words are italicized as a means of keeping them distinct from the English. Occasionally where English speakers might be confused by the absense of a word from the French that would be required in English, an English word is supplied in brackets as a temporary crutch.

Le weather was so warm, so clear!

One heard les blackbirds to whistle $\dot{a}$ la edge $d u$ forest, and in le meadow [of] Rippert, behind la sawmill, les Prussiens who did l'exercise. All that me tempted much more than la rule des participles; but I had la strength de to resist, and I ran very quickly toward la school.

3. A, de, y, en. $A$ and de are first introduced in lesson two, but both are used in several quite varied ways and they deserve a fuller discussion than was possible when the focus was upon gender and number. The pronouns $y$, and $e n$ are closely related to $\dot{a}$ and $d e$ and these can be included in the discussion. $Y$ and $e n$ are often quite difficult for English speakers since English has nothing at all 
like them, but they must be easily understood if one is to read French with comfort. Their use can be learned relatively easily if they are introduced at the same time as the related $\dot{a}$ and $d e$, and if they are first encountered in a text where the largest part of the vocabulary remains English.

This third lesson also includes a fairly detailed description of French verb sequences that correspond to such English phrases as "try to think", "help to swim", and "teach to count". In French many of these verb sequences require an $\dot{a}$ or $d e$ and so this is the natural place to introduce them. In order to prepare the student for having the French sign of the infinitive attached to the verb, the English word to- is joined to the English verb with a hyphen when infinitives appear in the reading passage for this lesson.

4. The Infinitive, Past Participle and Two Past Tenses. The verb system poses greater difficulties than any other aspect of French grammar, and exposure to its complexities begins with this lesson. The lesson introduces only 14 new forms, the first conjugation suffixes for the infinitive, the past participle, the imperfect tense, and the past definite tense. These are used repeatedly in the reading passages that $I$ have been giving to the students so they soon learn to recognize them. In lesson three the student saw "to-" attached to the verb as if it were a prefix. Now he encounters -er attached to the end of English verbs, and the transition is not difficult. Nor is there difficulty in learning that $-\dot{e}$ is often the equivalent of English "-ed", and the student will already have become familar with feminine and plural suffixes that can turn $-\dot{e}$ into -ée, és, or -ées. The difference in meaning between the imperfect and the past definite tenses is more subtile but it is simplified by the fact that the student learns the endings for these tenses in a context of familiar words.

To start with, only the first conjugation endings are used. This limitation conforms to the principle that the first priority is to provide a feeling for the overall system of the language. Once the system is well understood, the student will be able to tackle the numerous irregularities with less difficulty. To simplify the student's task, even irregular verbs are translated as if they are regular. The French verb faire 'do', for instance, is highly irregular, but it appears in the passages in such guises as doé. This could stand in place of an original fait (the irregular past participle of faire) but the learner need never be concerned with whether the do é that he encounters actually stands for the verb faire or for some other verb that is regular and that has a similar meaning. The actual forms of faire will not be introduced until much later when the student is ready to cope with the irregular forms. For now, 
forms such as doe will help him to master the system. The next sample suggests the type of passage made possible by the materials of lessons 3 and 4.

In pass -ant in-front-of la town-hall, I see-ai that there was $d u$ crowd stopé near $d u$ little screen aux posters. Since two years, it is de there that to-us are come-ées all les bades news, les battles lose-ées, les réquisitions, les orders de la headquarters; and I think-ai without myself stoper: $\ll$ What is-it that there is again? $\gg$

5. Some Relatives, Interrogatives And Conjunctions. This lesson introduces only four new words: qui, que, oú, and quand. All four are difficult words for each is used in a number of distinct ways and they differ markedly from familiar English usage. A passage that incorporates these words in their varied uses allows sentences to approach the original French considerably more closely.

6. Some Basic Vocabulary. Next, a score of very common French words are introduced. These include such conjunctions adverbs, adjectives and prepositions as et, mais, comme, très, autre, beaucoup, avec, and dans, and three nouns: jour, pere, and chose. These are words that appear constantly in the text. By turning them into French the passage assumes a considerably more French appearance, and this gives the students a satisfying sense of progress. The words introduced in this lesson, unlike those introduced in lesson 5 are relatively straight equivalents of English words, and this makes them easier to learn. As always, of course, the reading passage for this lesson gives students additional practice with the materials introduced earlier.

From this point onward somewhat larger blocks of vocabulary are introduced with each lesson and, in the hope of blunting the student's temptation to resort to brute memory, a new convention is adopted. The first few times that a new word is used, an English translation is placed directly above it. The final appearance of the translation is signalled by an asterisk, and by this time it is hoped most students will have absorbed its meaning without a deliberate struggle to memorize it. The reading passage accompanying lesson six, therefore, assumes the following form:

as

Then, comme I cross-ais la square in run-ant, le with

blacksmith Wachter, qui was there avec his apprentice in process de reader le poster, to me cry- $a$ : 
$\ll N e$ yourself hurry pas so much, little one; you $y$ will-arrive anyway enough soon $\dot{a}$ your school! $\gg$

I believe-ai que he himself tease-ait de me, and I all

enter-ai tout breathless in la little-e courtyard de Mr. Hamel.

Ordinarily, $a u$ commencement de la class, there was un great uproar qu'one hear-ait as-far-as in dans la street, les desks open-és, close-és, les lessons qu'one repeat-ait très loud tous together en oneself plug-ant les ears pour better learn-er, et la great ruler du teacher qui tap-ait sur les tables:

$\ll U n$ bit de silence! $\gg$

7. Pronouns. The French Pronoun system is considerably more complex than the English system, and since this lesson introduces all the personal pronouns of the language, the lesson is more demanding than any of its predecessors. By the time students get this far, however, they have grown accustomed to the method and my students have been able to manage the pronouns without undue difficulty. In spite of their large numbers, it is advantageous to introduce all the pronouns in a single block, for this allows a unified explanation of the system. A single chart can display the pronouns in a clear order and in a form that the student can easily consult.

The use of on and the difference between $t u$ and vous require brief explanation, and a somewhat fuller explanation is needed for the distinction between direct and indirect object pronouns and for the reflexives. Learning the pronouns is made easier by the experience that the students have already had by the time they reach this lesson. They are no longer surprised to find object pronouns before the verb and even the reflexive pronouns have appeared (translated as "myself", "yourself", etc.) and this eases the transition to the French forms. This lesson does introduce more new words and more new grammatical materials than earlier lesson, however, and the reading passage is correspondingly longer.

\footnotetext{
I

Je count-ais sur tout this confusion pour reacher my

mon bench sans be-er see-é; mais just that jour-there tout was tranquil, comme un morning de sunday. Par la I my window open-e, je see-ais mes classmates already dis-
} 
their

tribute-ès à leurs places, et $\mathrm{Mr}$. Hamel, qui pass-ait et his

repass-ait avec sa terrible ruler en iron under le arm. It [was] necessary opener la door et enter-er au middle de You $I^{*}$

that great stillness. Vous imagine, if je was red et if je had fear!

8. Borrowed Vocabulary. The most obvious aspects of borrowing between French and English are now described and, hereafter, when French and English words are sufficiently similar the words are incorporated into the reading passages in their French form. This is a relatively easy lesson and, in addition to introducing some new material, it provides additional practice with the pronouns.

\section{look at}

$E h$ well, no. Mr. Hamel me regarda sans anger et me say-a très softly:

$\ll$ Go quickly $\dot{a}$ ta place, mon little Frantz; nous [were] going commencer sans toi. $\gg$

Je leap-over-ai le bench et je me sit-ai quickly $\grave{a}$ mon desk. Then only, un bit relieve-é de ma fright, je notice-ai que notre teacher had $s a$ handsomee frock-coat green-e, son ruffled-shirt pleaté finely et la skull-cap de silk blacke embroider-ée qu'il ne wear-ait que les jours d'inspection ou de distribution de prises.

9. Demonstratives. As with personal pronouns, the characteristics of French demonstrative adjectives and demonstrative pronouns are described and gathered into a table, and they are then introduced into the text.

10. The Verb System: Infinitives, Participles, And The Seven Simple Tenses. By the time a student reaches this point he should feel quite comfortable with two tenses that English speakers usually find quite difficult, the imperfect and the past definite. He should have grown accustomed to finding tense markers suffixed to the verbs, and he will be familiar with subject-verb agreement. $\mathrm{He}$ will also be thoroughly familiar with the infinitive and the past participle. To these verb forms, this lesson adds the present participle (-ant) and the first conjugation suffixes for the four remaining simple tenses: the future, the conditional, the present subjunctive and the imperfect subjunctive. The student must aquire a feeling for the semantic differences among the various tenses. 
This lesson presents the heart of the verb system and it is probably the most difficult single lesson of the entire series, but the burden on the student is lightened by continuing to use only first conjugation endings. The vast complexities of the irregular verbs remain for the future. Two verbs, etre and avoir, are so pervasively irregular and so uniquely idiomatic in their usage that little would be gained by giving them an artificially regularized conjugation. They continue, for the present, to be translated into English.

To help students untangle the complexities of the verb system, brief formulas are written over the new verb suffixes the first few times they appear. These formulas inform the student of the tense, person, and number of the suffix. As the suffixes grow familiar the formulas are gradually eliminated, and the student is then on his own. As in earlier lessons, the new French forms (in this instance the verb suffixes) can be tabulated on a single page. This gives the student an overall perspective of the system. Gradually, as he reads he will master the details.

Besides, toute la classe had some chose d'extraordinaire et de solemn. Mais ce qui me surprise-a le plus, ce was de see-er au back de la room, sur les benches qui stay-aient empty-s ordinarily, des people du village seat-és et silent comme nous, le old Hauser avec son three-cornered-hat, le former mayor, le former postman, et then d'autres personnes still. Tout ce people-là appear-ait sade; et Hauser had bring-é un old primer eaté aux edges qu'il hold-ait wide open-é sur ses knees, avec ses big-es spectacles rest-ées across des pages.

11. Borrowed Vocabulary. Correspondences between English and French borrowed words are discussed in more detail here, so as to help students to recognize French words. Like lesson 8, this is intended as a relatively easy interlude between more difficult lessons. In addition to introducing a certain amount of new material it provides more practice with the simple tenses.

12. The Seven Compound Tenses. This is the second of three central lessons on the French verb system. Along with lessons 10 and 14, it introduces the student to the core of the tense system. By the time a student reaches this lesson, he should be gaining some comfort with the simple tenses and he will now learn that each simple tense has a corresponding compound tense. Since the compound tenses require être or avoir as auxiliary verbs, this is the most appropriate moment to introduce these two highly irregular 
verbs. Their full conjugations are tabulated and thus the students are able, at last, to face the irregularities of French verbs. These verbs, of course, are very common, and this means that students will soon have ample practice in recognizing their most common forms.

This is also a convenient place to describe passives, the reflexive verbs, and the set of intransitives that are conjugated with être, since all of these matters are intimately involved with the auxiliary verbs and with the compound tenses.

By this time the reading passages have incorporated a great deal of French. Some sort of half way point seems to have been reached, for at least half of the words are now French and the general structure of most sentences is essentially French. Beginning with this lesson, therefore, I italicize the English, rather than the French portions of the passage. This is a welcome signal to the students that a divide has been crossed. From now on an increasing part of the students' burden will be to clean up details and irregularities and to master more idioms and vocabulary. The more pervasive patterns of the language have already been presented.

The following passage, prepared at the level of lesson 12, includes a few of the notes by means of which $I$ have indicated the tense, person, and number of some verbs. The meaning of these notes should require no explanation.

$\mathrm{PqP}$ 3-S

While, que je m'étonnais de tout cela, Mr. Hamel

êtait climb-é dans sa chaire, et de la même voice soft-e et PqP 3-S

serious-e with which il m'avait receive-é, il nous say-a:

$\ll$ Mes children, c'est la last-e time que je vous do-e Ps Cm 3-S

la classe. L'ordre est come-é de Berlin de ne plus German

teach-er que l'allemend dans les schools de L'Alsace et de la Lorraine.... . Le new teacher arrive tomorrow. Today Pr Ind 3-S

c'est votre last-e leçon de français. Je vous ask-e d'être very attentifs.

13. Negatives, Interrogatives, And Relatives. The overall plan of this series of lessons has been to start with the most pervasive patterns of the language and to move gradually inward toward its more idiosyncrasic and irregular features. The assumption has been that the irregularities will pose fewer problems once the overall 
framework of the language is under control. The narrowing down to the more irregular aspects of the language is evident in this lesson. It introduces a larger number of lexical items than any earlier lesson-negatives, question words, and relative pronouns. Individually these cause few problems but there are a large number of them and each has its idiosyncrasies.

14. Irregular Verbs And Idioms. This is the third of the central trio of lessons on the verb system. It proves to be quite natural to introduce the suffixes of the second and third "regular" conjugations and the most common suffixes of the irregular verbs at the same time. More often than not, these are similar if not identical. It is possible, in fact, to list the vast majority of irregular verb suffixes and second and third conjugation verb suffixes in a single table. Some of these are like the first conjugation endings and a few are like the endings of avoir or être, and this reduces the burden upon the student. So long as the student does not have to reproduce these endings, they pose no insuperable difficulties. Notes that identify the verb and its tense assist the student the first few times that a new form appears.

Up to this point, a general principle has been maintained: the French form of a verb is never introduced unless the proper French suffix is available. Regularization has been used only when an English verb is substituted for the French. With suffixes for second and third conjugations and for irregular verbs at last available, it becomes possible to introduce the French forms of a number of very common but irregular verbs.

This lesson also introduces the student to several common idioms that use verbs such as aller, pouvoir, and falloir in ways that differ markedly from English.

Ces quelques words me overwhelm-èrent. Ah! les misérables, voilà ce qu'ils avaient post-é à la townhall.

Ma last-e leçon de francais! ... .

savoir Impft

Et moi qui savais à scarcely write-er! Je ne learnfalloir Cond

erais therefore jamais! Il faudrait therefore en stay-er là! Comme je m'en resent-ais now du time lose-é, des classes Inf

miss-ées à chase-ir les bird's nests ou a faire des sliding sur la Saar! Mes books que just now still je trouvais si tiresome-s, si heavy-s à carry-er, ma grammaire, mon 
histoire sacred-e me seem-aient à présent de old-s amis faire Cond

qui me feraient beaucoup de pain à quitter, c'est comme aller Impft

Mr. Hamel. L'idée qu'il allait partir, que je ne le verrais faire Impft

plus, me faisait forget-er les punishments, les blows de ruler.

Poor homme!

15. Adverbs and Adjectives. Except for the short list of adjectives and adverbs introduced in lesson 6 and those that are transparently similar to English, adverbs and adjectives have, up to this point, been translated into English. By now, however, the student should be thoroughly accustomed to number and gender agreement, and to finding adjectives after their nouns. This lesson introduces many of the most common French adjectives and adverbs and since many of these are irregular it tabulates their various forms. The lesson describes comparison and it introduces many comparatives and superlatives. Like lesson 13, it presents a considerable range of irregular details, but the student should now have a clear enough grasp of the system to allow him to see how the details fit into the larger picture. This should make these new forms relatively easy to recognize and, of course, he need not try to reproduce them.

16. Past Participles and Reflexives. This is the first of several lessons that spell out the details of particular tenses and verb forms. A considerable list of irregular past participles is given, tabulated according to the varieties of irregularity, and students should soon grow comfortable with these irregularities. This lesson also adds to the store of first conjugation verbs that students should begin to recognize, and it discusses the reflexives in more detail than was possible earlier. Examples are given of the irregular relationship between some non reflexive verbs and their corresponding reflexives.

17. Number And Prepositions. Unitl this point numbers have all been translated into English and only the short list of prepositions introduced in lesson six have been in French. The number system is now described and a considerable range of prepositions is added to the student's stock. The reading passage for each of the lessons in this part of the program is quite long since many of the details now being introduced can no longer be expected to occur 
within the limits of a short passage. French has been accumulating steadily, however, and by the time students have reached this stage the reading passages are predominantly French.

last

C'est en l'honneur de cette derniere classe qu'il avait mis ses beaux clothes du sunday, et maintenant je comprenais pourquoi ces vieux du village étaient venus s'asseoir au end de la room. Cela semblait dire qu'ils regrettaient de ne pas y être venus plus souvant, à cette school. C'était aussi comme une façon de thank-er notre forty

teacher de ses quarante years de bons service, et de pay-er leurs respects à la nation qui s'en disappear-ait. . .

18. The Present Indicative And Idioms. The various kinds of irregularities of the most irregular of all the tenses are surveyed in this lesson and a number of examples are given. The goal, as always, is not to have students memorize these irregularities but to get a feeling for the range of possibilities so that they will be able to recognize them when they encounter them in context. The lesson also describes a few very common idioms.

19. Nouns. Many French Nouns are so transparently similar to their English equivalents that it has been possible to introduce a large number of them into the reading passages. Of all the grammatical elements of French, however, nouns are the last to receive explicit attention. In part, this is because nouns are relatively easy to learn. In part, however, it is because few individual nouns are very common, in spite of the fact that the language has more nouns than all other words combined. In the beginning little would have been gained by asking a student to remember many nouns because each would have appeared so rarely in the text that he was reading.

This lesson concentrates upon the most common nouns. Some words for body parts, animals, people, the natural environment, and units of time are listed. A large proportion of these have given rise to related English words of more specialized meaning (brasbracelet, terre-terrestrial, homme-humanity, etc.) Related English words are given with the French word wherever possible. This should help students remember particular words, but even more important it should give students the idea that it is reasonable to search their minds for such related English words as they encounter new French vocabulary.

20. Imperfect And Present Subjunctive. The irregularities of 
these two related tenses are discussed just as the irregularities of the present tense were discussed in lesson 18. The use of the subjunctive is described in more detail than was possible earlier and some of the conjunctions and verbs that govern the French subjunctive are introduced.

21. Remaining Simple Tenses. The future, the conditional, the past definite and the imperfect subjunctive are described and their irregularities are surveyed. By the time students reach this lesson they are able to read passages that are in French in all essentials. Only certain less common items of vocabulary are translated into English.

J'en étais là de mes réflexions, guand j'entendis appeler mon nom. C'était mon tour de reciter. Que n'aurais-je pas donne pour pouvoir dire tout an full cette fameuse rule des participles, bien loud, bien clair, sans une faute; mais je me blunder-ai aux premiers words, et je restai up à me sway-er dans mon bench, le coeur gros, sans dare-er raise-er la tête.

22. Building Vocabulary. The final lesson of the series consists of some rather discursive suggestions about how to go about building vocabulary. The conventions of French dictionaries are described, but students are encouraged to read widely and to use a dictionary as little as possible. They are urged to try to absorb the meaning of words gradually as they are faced in context rather that by attempting to commit them to memory by brute force.

The reading passage for this final lesson is given in its full original French. The student is encouraged to look up as few words as possible and to try instead to gain practice at guessing the meaning of unfamiliar words. To help him when he gets stuck, footnotes translate those words that would have been given in English in earlier passages. By the time students have finished this lesson they are ready for one of the many available reading books that are equipped with footnotes, or a glossary. With the help of a dictionary they can work their way through unedited materials.

\section{Disadvantages And Advantages}

The disadvantages that are inherent in the method I have described must not be minimized. The mixed texts, for one thing, are unaesthetic. Those with a sensitive appreciation for the languages may find the language salad that the method requires to be frivolous if not repellent. I would counter this criticism by 
pointing out that the childish materials that we give to beginning students in conventional French courses are even less aesthetically pleasing. If we are to worry about delicate sentivities, it is surely the sensitivity of the students who must read the materials about whom we should be concerned. Those already skilled in the languages who find the mixed texts distasteful need not look at them. Students have no choice.

A more serious problem is posed by pronunciation. I have refrained from asking my students to pronounce anything at all in French, but now and then they mention French words and it is apparent that their ideas of the pronunciation are entirely eccentric. Some students seem willing to read in happy ignorance of the native pronunciation even while admitting that they cannot refrain from inventing their own pronunciations for their private use. Other students seem very much to need to know how the words are pronounced. They are- bothered if they cannot subvocalize as they read. Some even want to be able to read aloud. I have offered two kinds of help to such students.

First, I have provided them with a description of French pronunciation. More accurately, I have given them description of how the letters of French are pronounced under varying circumstances. Students can refer to this when they feel they need help. The relationship between French pronunciation and orthography is so complex, however, that this is a much less than satisfactory solution. Students with no exposure to the spoken language find it difficult to use a written description.

My second method of helping students with pronunciation has been to record the text, French and English all mixed together, on tape. Students can then listen to the tapes as they follow the written text on paper. At first I thought of this as almost a joke, but it proved far easier and more natural to read the texts aloud than I had expected. One has a certain problem with articulatory acrobatics as one repeatedly jumps back and forth from French to English pronunciation, but the reasonable solution to this difficulty is aim for accurate French pronunciation and let the English words aquire a French quality if that makes the text easier to read. I asked a native French speaker to read some of the text for me and I was amused to find that as he read and as he grew accustomed to his task, his pronunciation of English words became more and more accented. If the intention is to give students a feeling for French pronunciation, the distortion of the English words would seem to be of little consequence.

Reading the mixed texts aloud proved less artificial than I had 
anticipated. When first inspected, the texts certainly look artificial but when working through them in sequence it proves quite natural to read them as a coherent language. They can easily be given a natural intonation and, while one must slip rapidly back and forth between words of English and French origins, these meld together into a single communication system that soon loses its initial look of implausibility. Students who have used the tapes have reported them to be quite helpful. Not only did the tapes give them a sense of what the language sounds like and a sense of how the letters are related to the sounds, but the rhythm and intonation of the sentences and the varying emphasis that readers give to different words made the passages easier to understand. The recordings helped students to gain a feeling for the structure of the sentences.

Some students have felt no need for help with pronunciation and $I$ have let them decide for themselves whether or not to spend time with the tapes. The tapes cannot solve all pronunciation problems but for some students they seem to cut through the worst of their difficulties.

The final and most obvious disadvantage of my method, of course, is that when students have finished my materials they can neither write, nor engage in conversation. For many students, I believe, the advantages of rapid progress in reading far outweigh the limitations on conversation, but other students would certainly prefer a course which promises progress in the spoken language as well. My method is not the right one for all students.

One question that must arise is whether a student who has learned to read with my materials will be handicapped if he later wants to add a conversational ability to his repertory of skills. I cannot yet give a confident answer to this question, but I expect few difficulties. It may be that a student who has invented his own pronunciations will need some corrective relearning, but the feeling for structure and the considerable stock of receptive vocabulary that my method provides should allow the student to make relatively rapid progress once he is motivated to work on the spoken language. On this, however, we need more experience.

The disadvantages of the method are counterbalanced by a number of striking advantages. Several of my students have told me that they became so caught up in the story they were reading, so eager to find out what was going to happen next, that they found it difficult to spend as much time on the grammar as they felt they should. In response, I have always told them that what really mattered was their ability to understand. The grammatical 
notes were provided only as a means of helping them to find their way through the reading. If they could read with little attention to the notes, then so much the better. It is a rare language course that allows beginning students to become this engrossed in the content of their reading. A course that can motivate students to read in this way and that can spare the student the tedium of childish reading materials would deserve to be taken seriously even if it had little else to recommend it.

But the method has some other advantages too. It allows the student to focus his concious attention upon the more pervasive characteristics of the language and to leave the eccentricities to sort themselves out gradually. Sooner or later the language learner must cope with the eccentricities but learning to recognize them is far easier than learning to produce them. A beginning student who is asked to speak or write must, if he is to avoid multiple errors, keep a hundred details in his mind at the same time. With no need to produce the language, progress can be much more rapid and if a student finally decides that he wants to speak or write, his experience with hundreds of pages of mature French will have given him a sense of the language, and even some of its eccentricities will have come to seem natural-to "sound right"-with little explicit attention ever having been directed toward them.

The changing proportions of English and French in the text give the student a constant and visible measure of his progress. As the weeks go by he can watch the text shift inexorably toward French. At every point he can see just how far he still has to go.

Finally, the method focusses much of the students conscious attention upon the area of language that is of greatest concern to the ordinary speaker: the meaning. Always he must read for understanding. The grammar is given only as an means to the end of extracting meaning. New words and new constructions are always learned in a familiar context. At every stage the student can bring to his task a full and mature language system. He learns by incorporating new linguistic elements into this already mature system. As each new element sinks back into semi-conscious and then into unconscious familiarity, it becomes part of the context within which the next elements are learned. He never needs to be frustrated by the kind of fragmentary isolated knowledge that ordinarily limits elementary language students.

\section{Conclusions}

The early lessons in the sequence are shorter than those that 
come later. This is because the first language features covered are so common that a very few pages of text are enough to give adequate practice. Later lessons cover rarer aspects of the language and some of these may not appear at all in a short passage. For this reason the later lessons have much longer passages and, to make such a long passage profitable, each of these lessons also introduces more material. At the start, therefore, my students cover three or even four lessons each week. Later, they work through no more than two. In the course of the term they read about 70,000 words of text. If only half these words are in French, they are still well ahead of first term students in more conventional classes.

Students with no background in French have had no trouble working through my materials in a single 14 week term and they report spending no more than four or five hours each week on the lessons, including one hour in class. Convincing comparisons with courses that use different techniques are difficult because of differences in course goals, and because of varying student background and motivation. My students may have been stimulated by the experimental nature of the situation. On the other hand, they were not taking the course officially and they had no need to cram for an examination or to worry about a grade. My preliminary estimates suggest that my students reach at least as far as the level of second year high school French, and they do about as well as students who take one term of the special reading course offered by the Romance Languages Department of the University of Michigan. These latter students, however, have reported that they spent about twice as much time each week on their French as do my students and all indications are that students in the conventional reading class find their French to be far less agreeable than do mine.

I have often been asked how I would handle languages, such as Russian, that do not use the Roman alphabet, or, even worse, languages such as Arabic or Hebrew, in which the direction of writing is different from English. For Russian, I would be tempted to introduce the Cyrillic alphabet by first teaching students to read English that has been transcribed into Cyrillic. Once the alphabet is mastered it would seem possible to proceed much as I have done with French. It might be possible to teach Arabic and Hebrew orthography in the same way but mixing right-to-left Arabic or Hebrew into the same passage with left-to-right English might pose insuperable problems. Since we read with a series of discrete fixations and not with a continuous sweep of our eyes, however, it 
might even be possible to mix together words of differing directions in the same passage. The possibilities for Chinese seem, at first sight, to be quite promising. Chinese characters could easily be sprinkled in among the English words in gradually increasing proportions. The reader might even vocalize the characters by means of English words. The method would make it difficult to capitalize upon the considerable phonetic component of the characters, however, and this might be a serious drawback. The problems posed by different writing systems, however, will only be clearly seen when experiments are made with practical lessons.

Preparing materials for a course such as I have described is a laborious process, but it can have a peculiar and rewarding fascination. It has liberated me from all sorts of notions about the purity of my language and it has shown me how easy and natural the processes of borrowing between language can be. And, of course, I have also had the satisfaction of watching students avoid some of the agonies of language learning that I still remember so vividly from my own education. I would be endlessly pleased if others found the methods that I have proposed to be sufficiently intriguing to merit imitation.

\section{REFERENCES}

Burling, Robbins. 1968. Some outlandish proposals for the teaching of foreign languages. Language Learning 18.61-75.

Postovsky, Valerian A. 1974. Effects of delay in oral practice at the beginning of second language learning. Modern Language Journal 58.

Postovsky, Valerian A. 1975. The priority of aural comprehension in the language acquisition process. Paper presented at the 4th. AILA World Congress, Stuttgart. 